\title{
Percepção dos Estudantes de Medicina sobre o Uso da Metodologia da Problematização durante a Graduação
}

\author{
How Medicine Students view the Use of Problematization Methodology \\ in Undergraduate Training
}

\author{
Rejane de Carvalho Santiago ${ }^{I, I I}$ (iD \\ Vardeli Alves de Moraes ${ }^{I}(\mathbb{D}$ \\ Rogério José de Almeida ${ }^{I I} \mathbb{D}$
}

\section{PALAVRAS-CHAVE}

- Educação Médica.

- Aprendizagem.

- Metodologia da Problematização.

- Medicina.

Introdução: As Diretrizes Curriculares Nacionais (DCN) para Graduação em Medicina estabelecem que o curso deve ser centrado no aluno como sujeito da aprendizagem. Devem-se utilizar metodologias que privilegiem a participação do aluno na construção do conhecimento. O objetivo deste estudo foi compreender a percepção do aluno de Medicina acerca da metodologia da problematização na unidade Problema Integrador de Competências (PIC) da Pontifícia Universidade Católica de Goiás (PUC Goiás). Método: Trata-se de uma pesquisa transversal descritiva com abordagem qualitativa. Os dados foram coletados por meio de entrevista semiestruturada que se utilizou de um roteiro de temas previamente confeccionado. Entrevistaram-se 30 acadêmicos do primeiro ao décimo segundo módulo sobre a unidade PIC que é desenvolvida por meio da metodologia da problematização com a inserção do arco de Charles Maguerez. Para a análise dos dados, adotou-se Teoria Fundamentada nos Dados ou Grounded Theory. Resultados: Com os resultados obtidos após realização da transcrição e análise das entrevistas, foi possível criar as seguintes categorias explicativas do fenômeno investigado: pontos fortes, frágeis e melhorias; características do aluno e do professor no PIC; contribuições do PIC para formação médica. Por meio da análise das categorias explicativas, evidenciaram-se a eficiência e as contribuições da funcionalidade e aplicabilidade da metodologia da problematização na unidade do PIC. Constatou-se que os discentes que participaram desta pesquisa conseguiram desenvolver habilidades relacionadas à comunicação, pesquisa, resolutividade e proatividade, aprenderam a trabalhar em equipe e ouvir e respeitar a opinião dos colegas, tornaram-se pessoas mais críticas e entenderam a importância de enxergar o paciente de forma holística; todos aspectos imprescindíveis para a formação em Medicina. A partir da percepção dos acadêmicos de Medicina, foi possível evidenciar que a metodologia da problematização inserida no campo da formação médica ainda tem fragilidades tanto na formação do aluno quanto na atuação do professor mediador. Conclusões: Os resultados aqui apresentados poderão servir para que os cursos de Medicina que se utilizam dessa metodologia possam fomentar estratégias que visem à sua correta aplicabilidade. 


\section{KEYWORDS}

- Medical Education.

- Learning.

- Problematization Methodology.

- Medicine.

Recebido em 23/3/20

Aceito em 16/9/20

\section{INTRODUÇÃO}

Questões relacionadas aos métodos adotados no processo de ensino-aprendizagem têm ganhado destaque em decorrência da preocupação crescente com a formação de médicos que saibam lidar com as dimensões sociais, subjetivas e culturais das pessoas. $\mathrm{O}$ modelo tradicional de ensino, baseado na perspectiva de Flexner, favorece o aprendizado em disciplinas, mas é fortemente centrado no professor e marcado pela fragmentação dos indivíduos ${ }^{1}$.

O ensino em saúde, especificamente na medicina, tem se mostrado ineficiente quando centrado nos aspectos puramente biológicos, que se desvinculam dos aspectos subjetivos e desconsideram os determinantes sociais de saúde. Nesse contexto, as metodologias ativas de ensino surgem como uma forma de superar as tradicionais por proporcionarem aspectos de integralidade, ética e humanização na formação do médico ${ }^{2}$. Nessa ótica, vislumbra-se a formação de profissionais médicos com maior capacidade de agir na resolução dos problemas de saúde dos indivíduos e da coletividade ${ }^{3}$.

As Diretrizes Curriculares Nacionais (DCN) para Graduação em Medicina, em seu capítulo III, estabelecem que o curso deve ser centrado no aluno como sujeito da aprendizagem, tendo apoio do professor como facilitador e mediador do processo, visando à formação integral. Orientam ainda que o curso deve utilizar metodologias que privilegiem a participação do aluno na construção do conhecimento, isto é, utilizandose de metodologias ativas de ensino ${ }^{4}$.

As metodologias ativas de ensino, na formação em medicina, têm se embasado principalmente em duas abordagens teórico-práticas: metodologia da problematização e Aprendizagem Baseada em Problemas (APB) ${ }^{5}$. Nesse cenário, a Pontifícia Universidade Católica de Goiás (PUC Goiás) tem um curso de Medicina que se baseia nessas duas metodologias ativas. Com relação à metodologia da problematização, ela é inserida na matriz curricular denominada de Problema Integrador de Competências (PIC), na

\section{ABSTRACT}

Introduction: The National Curriculum Guidelines (DCN) for undergraduate medical training establish that courses should be centered on the student as a subject of learning and use methodologies geared toward student participation in the construction of knowledge. The aim of this study was to understand how medical students view the use of problematization methodology in the Competence Integrating Problem (PIC) unit at the Pontifical Catholic University of Goiás (PUC Goiás). Method: This cross-sectional, descriptive study adopts a qualitative approach. The data were collected through semi-structured interviews based on a list of topics prepared in advance. Interviews were conducted with thirty academics from the first to the twelfth modules of the PIC unit, the methodology of which course is based on problematization combined with the incorporation of the Charles Maguerez Arch. Grounded Theory was used for the data analysis. Results: The results from the interview transcription and analysis, three explanatory categories were created for the investigated phenomenon mely: Positive, negative and improvement points; PIC student and teacher characteristics; PIC contribution to explanatory categories demonstrated functional and applicable contribution problem solving, proactivity, learning to work in a team and to listen and respect the opinions of colleagues, critical thinking, and a holistic understanding of the patient, for the purposes of medical training. Drawing on the views of the medical students, problematization methodology used in the field of medical education was shown to still have weaknesses both in terms of the student's training and the performance of the mediating teacher. Conclusions: The results of this study may be used to ensure that medical courses that use this methodology adopt strategies aimed at its correct applicability. 
- Pontos-chave: etapa realizada em sala de aula, em que o professor leva os alunos a uma reflexão sobre as possíveis causas da existência do problema em estudo.

- Teorização: etapa realizada em sala de aula, em que os problemas apontados são teorizados por meio de artigos científicos, legislações, entre outros.

- Hipóteses de solução: etapa realizada em sala de aula, em que são elaboradas e planejadas ações de dispersão visando às possíveis soluções para o problema em estudo.

- Aplicação à realidade: etapa realizada no cenário de prática, em que as ações de dispersão planejadas são executadas como um compromisso social, com uma devolutiva prática de solução para o problema ${ }^{9}$.

A estrutura metodológica do PIC é desenvolvida de igual forma nos 12 módulos do curso. Como os cenários de prática vão se alterando, os problemas vivenciados pelos estudantes também mudam. Em geral, são discutidos no máximo dois casos-problema ao longo de um semestre letivo. Ao final de cada aula do PIC, o professor mediador do grupo atribui uma nota a cada aluno, e este se autoavalia e atribui a si mesmo uma nota. Ambas as fichas de avaliação são divididas em competências, habilidades e atitudes.

Essas novas metodologias de ensino se fundamentam na construção da aprendizagem. Ao contrário do método tradicional em que o ensino está centrado na autonomia do professor e na fragmentação das disciplinas, nas metodologias ativas a autonomia passa a ser do estudante que faz a busca e construção do seu conhecimento com uma visão integrativa ${ }^{10}$. As metodologias ativas de ensino-aprendizagem se apresentam como modelo inovador para a formação médica. Por se tratar de um modelo diferente do tradicional, existe uma quebra de conceitos, historicamente construídos, sobre o processo do aprender ${ }^{11}$.

Nesse sentido, o foco da problemática exposta neste estudo se debruça sobre a inserção da metodologia da problematização na formação médica. Tem como objetivo compreender a percepção do aluno de Medicina acerca da metodologia da problematização na unidade PIC.

\section{MÉTODOS}

Trata-se de um estudo transversal descritivo com abordagem qualitativa. Esse tipo de estudo permite a visualização da situação de uma população em um determinado momento, como se tirasse uma foto da realidade atual do fenômeno ${ }^{12}$. A pretensão deste estudo é compreender, em níveis mais aprofundados, tudo o que se refere ao homem como indivíduo ou membro de um grupo ${ }^{13}$.

O recorte empírico estabelecido na presente pesquisa situou a coleta de dados no curso de Medicina da PUC Goiás, que se utiliza da metodologia da problematização como unidade pedagógica da matriz curricular em todos os módulos.

O procedimento metodológico utilizado neste estudo compreendeu a realização de entrevistas com os alunos do primeiro ao $12^{\circ}$ módulo, sendo dez do primeiro ao quarto, dez do quinto ao oitavo e dez do nono ao $12^{\circ}$, totalizando 30 alunos. Como a pesquisa qualitativa não depende de cálculo matemático amostral, a divisão em três grupos (início, meio e fim do curso) e o quantitativo de estudantes em cada grupo ocorreram de forma a verificar a percepção dos alunos em relação ao PIC ao longo do curso de Medicina.

Os critérios de inclusão adotados pelo estudo foram: alunos que estivessem cursando do primeiro ao $12^{\circ}$ módulo e que participavam da unidade PIC. Os critérios de exclusão foram: alunos não matriculados na unidade PIC e aqueles transferidos de outras instituições de ensino superior que não tinham vivenciado a metodologia desde o início do curso.

$\mathrm{O}$ recrutamento dos acadêmicos se deu a partir de visitas à sala de aula durante as aulas do PIC em todos os módulos. Realizou-se o convite para participarem da pesquisa, e os entrevistados foram selecionados de forma aleatória após se apresentarem voluntariamente. A partir do momento em que entendiam o objetivo da pesquisa, vários alunos se dispusera $\mathrm{m}$ a participar, e as entrevistas foram agendadas com aqueles que demonstraram interesse.

No início da entrevista, apresentou-se o Termo de Consentimento Livre e Esclarecido (TCLE) com os dados sobre a pesquisa para que fosse lido e assinado, desde que estivesse de acordo, pelo participante voluntário da pesquisa.

As entrevistas ocorreram em uma sala nas dependências da PUC Goiás, em um ambiente de silêncio (utilização de um gravador), um lugar em que ninguém ficasse por perto (poderia constranger o entrevistado) e sem preocupação com tempo (as entrevistas tiveram uma duração que variou de uma a uma hora e meia).

Dentre as várias técnicas qualitativas de investigação, optou-se nesta pesquisa por utilizar a entrevista semiestruturada que tem como característica questionamentos básicos que são apoiados em teorias e hipóteses que se relacionam ao tema da pesquisa. Esse tipo de entrevista favorece não só a descrição dos fenômenos sociais, mas também sua explicação e a compreensão de sua totalidade ${ }^{14}$. As entrevistas foram realizadas entre fevereiro de 2019 e julho de 2019 com a utilização de um roteiro de temas específicos para a perspectiva adotada.

A análise das entrevistas se baseou na perspectiva da Teoria Fundamentada nos Dados - TFD - (Grounded Theory). Essa perspectiva de analisar dados qualitativos busca compreender a realidade a partir da percepção ou do significado que certo contexto ou objeto tem para o indivíduo, de modo a gerar conhecimentos, aumentar a compreensão e proporcionar um guia significativo para a ação. Compreende uma metodologia qualitativa de investigação que extrai aspectos significativos das experiências vivenciadas pelos atores sociais, o que possibilita a interligação dos constructos teóricos e potencializa a expansão do conhecimento ${ }^{15}$.

O processo de análise se iniciou com a "Codificação Aberta" que ajudou a explorar analiticamente os dados, abrindo-os a todas as direções de sentidos. Assim, os conceitos foram identificados e processados com atividades do tipo examinar, comparar, conceituar e categorizar os dados. O segundo passo executado foi a "Codificação Axial". Essa codificação se fez necessária em função do grande volume de conceitos (códigos) originados na etapa anterior. Nessa fase, reuniram-se conceitos similares, com características aproximadas, e analisaram-se os conceitos selecionados, que foram agrupados conforme suas características peculiares. O terceiro passo executado foi a "Codificação Seletiva", considerada a fase mais abstrata. Nesse momento, já com as categorias analíticas propriamente ditas, reorganizaram-se todas elas, de modo a fazer interconexões e identificar uma categoria que englobasse todas as outras de maneira mais completa. Nessa fase, ocorreu o refinamento da descrição do fenômeno ${ }^{15,16}$.

REVISTA BRASILEIRA DE EDUCAÇÃO MÉDICA

3 44 (4) : e161; 2020 
Antes de iniciar a coleta de dados, o presente trabalho foi encaminhado e aprovado pelo Comitê de Ética e Pesquisa (CEP) da Universidade Federal de Goiás (UFG) (Parecer no 3.003.088) e pelo CEP da PUC Goiás (Parecer no 3.027.281).

\section{RESULTADOS}

Após a realização, transcrição e análise das entrevistas, com posterior codificação das falas dos entrevistados, surgiram as seguintes categorias explicativas do fenômeno: pontos fortes, frágeis e melhorias; características do aluno e do professor no PIC; contribuições do PIC para formação médica.

\section{Pontos fortes, frágeis e melhorias}

Quanto aos pontos fortes, identificaram-se, no grupo entrevistados do primeiro ao quarto módulo, opiniões convergentes em relação aos pontos fortes das aulas do PIC. As observações positivas mais recorrentes foram: discutir assuntos que não estavam relacionados somente com a área biomédica, aprender a estudar, saber identificar a relevância dos artigos, ter autonomia e proatividade nos estudos, saber respeitar a opinião dos outros colegas, opiniões de outas profissões e aprender a trabalhar em equipe multidisciplinar.

Eu considero algo que pode acrescentar muito na nossa formação. A gente aprende estudar, a gente aprende a lidar com opiniões diferentes, a gente aprende a lidar com pessoas de áreas diferentes (E6 M4).

O grupo de professores ser uma equipe multidisciplinar, eu acho maravilhoso, porque tem uma contribuição sempre diferente, visões diferentes, olhares diferentes. Eu acho que isso já é uma iniciação de trabalho em equipe (E8 M4).

Outros pontos fortes foram: obter discussões enriquecedoras de um mesmo artigo que apresenta várias visões diferentes, percepção da realidade por meio do contato com a comunidade, resolução de problemas, estimular um olhar crítico e holístico, desenvolver a parte organizacional e falar em público.

Eu acho um ponto forte do PIC, primeiro ele é um caso colhido por nós, ele é um caso real, muito real, que representa a realidade daquela população que a gente está inserida. Eu gosto das discussões porque às vezes falam o mesmo artigo, mas apresentam perspectivas diferentes, acho muito importante (E3 M3).

Eu acho que é uma oportunidade de treinar várias habilidades, como a interação em grupo, a questão de conhecimento, a problematização e uma visão holística. Eu acho que uma oportunidade que a gente tem de treinar várias habilidades $e$ adquirir novas também (E10 M4).

Em relação ao grupo de acadêmicos que estavam cursando do quinto ao oitavo módulo, identificou-se que os discursos foram convergentes com o grupo anterior. Entre os pontos fortes elencados, destacaram-se os seguintes: estar em contato com a comunidade e vivenciar a realidade dos fatos, aprender assuntos que não estão inseridos na matriz curricular, falar em público, presença de profissionais de outras áreas em sala de aula, discussões, possibilidade de os alunos se tornarem mais críticos e deixarem de ser agentes passivos, e estímulo à pesquisa:

Só o fato de estar estudando na realidade que a gente está inserido, eu acho isso extremamente positivo. Outro ponto, estimula a pesquisa, eu gosto dessa ideia de poder agir (E15 M8).

No grupo de acadêmicos que estavam cursando do nono ao décimo segundo módulo, foram também convergentes as falas em relação aos pontos fortes, principalmente nos itens: aprender a falar em público, respeitar a opinião do colega, pesquisar artigos, resolutividade de problemas, discussões, compreensão do trabalho em equipe, busca pelo conhecimento colocando o aluno como sujeito da aprendizagem, aprendizado de outros assuntos que não sejam biomédicos e presença de uma equipe multiprofissional nas aulas.

Um ponto extremamente importante é que permite compreender o trabalho em equipe, dá oportunidade de ouvir o colega. Estimula a estudar constantemente, você mesmo corre atrás dos próprios conceitos e aquisição de novos conhecimentos e isso te prepara para o mercado de trabalho. Coloca o estudante como sujeito principal do aprendizado. Ele é responsável pela sua própria construção de conhecimentos e habilidades (E29 M12).

Um fato que merece destaque nesse grupo foi a afirmação da importância da proximidade do professor com o aluno. Tal fato faz diferença no processo de ensino-aprendizagem.

\footnotetext{
Uma questão que eu acho muito real é o fato de a gente ter vários professores sentados ao nosso lado tirando a distância vertical que o ensino tradicional, que o professor despeja conteúdo no aluno. Lá no PIC a gente está lado a lado com um profissional que tem experiência em uma área, que está aberto para discutir, escutar nossa opinião. Eu acho uma metodologia inteligente, ela instiga no aluno o interesse de ser o protagonista no processo de aprendizagem (E27 M11).
}

Após a análise das narrativas de todos os grupos envolvidos acerca dos pontos fortes das aulas do PIC, ficou clara a importância dessa unidade no curso de Medicina. Independentemente do módulo em que o acadêmico estava, tais pontos fortes foram praticamente os mesmos.

Já no que se refere a pontos frágeis sobre as aulas do PIC, foi possível verificar que os alunos que estavam cursando do primeiro ao quarto período apresentaram um sentimento negativo e frustrante em relação à organização das aulas, principalmente no que concerne às dispersões (devolutiva à comunidade) que não são realizadas e/ou são feitas de forma que não atingem a comunidade-alvo.

Mas aí tem a questão, por exemplo, do nosso primeiro PIC de ser desorganizado, tanto é que não teve devolutiva (E3 M2).

Nas dispersões, eles só querem publicar coisas na internet, querem publicar coisas no Instagram, fazer folder para divulgar nas redes sociais. Eu acho que isso é ridículo, porque as pessoas não me seguem, então como é que eles vão ver isso? (E7 M4).

Outro ponto frágil que deixou esse grupo desanimado e frustrado foi

REVISTA BRASILEIRA DE EDUCAÇÃO MÉDICA

4 44(4) : e161; 2020 
em relação ao despreparo de alguns dos professores que estão presentes nas aulas do PIC. Foi possível verificar nas narrativas o descontentamento dos alunos em relação às atitudes, às habilidades, às condutas e à forma de avaliação de alguns professores.

Todo semestre tem professor que deixa ir, que dá nota injusta que não, por exemplo você está debatendo aí você olha para o professor ele está mexendo no celular (E7 M4).

Muitos professores não sabem como dar a aula, mas acho que tinha que ter um preparo maior, porque eu acho que os professores não têm um preparo para o PIC (E5 M3).

Tais perspectivas não foram diferentes com o grupo de alunos que estavam cursando do quinto ao oitavo módulo quando questionados se o PIC apresentava pontos frágeis. As narrativas desse grupo corroboram as narrativas do grupo anterior, pois se sentiram frustrados sobre a não realização das dispersões, e, quando feitas, elas não atingiam os objetivos propostos, não devolviam para comunidade. Além disso, o grupo apontou a desorganização, o descompromisso tanto dos alunos quanto dos professores e a falta de professores, o que demonstra o descompromisso relatado pelos alunos.

O pessoal, principalmente quando chega na dispersão, sempre quer votar naquela que é mais fácil, mais rápida, e que aí acaba ficando a mesma coisa. As dispersões poderiam ser mais focadas, os professores poderiam orientar mais. Os professores não fazem questão, os alunos também não (E14 M8).

Eu noto assim, é que o descompromisso não é só por parte dos alunos, às vezes os professores também estão desmotivados. Quando algum professor falta vai juntando os pequenos grupos, isso já fica bagunçado. E isso vai se naturalizando tanto que chegou uma época teve um semestre que estava faltando tanto professor que o pequeno grupo praticamente não existia, sempre juntava e a gente achava isso normal. O coordenador também via isso como normal ou fechava os olhos para isso (E16 M8).

As falas dos acadêmicos entrevistados que estavam cursando do nono ao décimo segundo módulo demonstraram, assim como nos dois grupos anteriores, o sentimento de negatividade e frustração em relação às mesmas situações já citadas. Entre as queixas principais desse grupo, destacam-se as dispersões que não atingem os objetivos propostos, a falta de interesse tanto dos alunos quanto dos professores e a questão da organização.

Não vejo uma devolutiva tão eficiente para a sociedade, aí começam a votar em post no Instagram, fazer banner, colocar um banner em um local e no máximo arrumar alguém para fazer uma palestra pra gente para o próprio PIC (E22 M10).

Acho que tem tanto professores quanto alunos desinteressados porque não acreditam no projeto ao longo dos doze módulos. Minha impressão é que nem os professores nem os alunos levam tão a sério como deveria ser levado. Tem professor que não tem interesse em saber se a gente fez ou deixou de fazer, não cobra, às vezes eles mesmos abrem o celular (E27 M11).

De modo geral, sobre os pontos frágeis analisados em todos os grupos, foi possível observar a insatisfação e frustração dos alunos em relação às dispersões não executadas ou executadas sem atingir os objetivos, o descaso tanto de alunos quanto de professores e a falta de preparo de alguns professores.

No que se refere às melhorias que podem ser implementadas no PIC, identificaram-se, nos alunos do primeiro ao quarto módulo, as seguintes sugestões: capacitação dos professores no que se refere à conduta, à postura e à forma avaliativa e a necessidade de docentes mais interessados. Os entrevistados deixaram claro, em suas narrativas, que os professores apresentam atitudes diferentes: alguns são muito rígidos e outros deixam os alunos mais soltos.

Acho que ter uma padronização, uma capacitação dos professores do PIC, eu acho que é uma coisa que precisa acontecer urgente, porque a questão da avaliação [é] desigual. Todos tinham que falar a mesma linguagem, mas eu sei também que depende do aluno. Mas eu percebo muito é que, quando o professor ele busca e atrai as pessoas, incentiva, melhora muito o rendimento (E7 M4).

Às vezes contar mais com o professor que está mais interessado. Eu acho que se tivesse professores mais preocupados em estar ali e cumprir a proposta e fazer essa promoção para comunidade, eu acho que seria mais proveitoso (E2 M2).

Quanto às melhorias, os alunos que estavam cursando do quinto ao oitavo módulo apontaram as mesmas necessidades do grupo anterior. Nos depoimentos deles, observou-se a imprescindibilidade de padronizações nas avaliações, nos treinamentos e na capacitação dos professores para que o PIC se torne mais atrativo.

O que eu melhoraria, seria esses professores que não demonstram muito interesse, preparar um pouco esses professores, mostrar para eles positividade, o que tem de legal, para gente selecionar melhor os professores que têm mais interesse no PIC (E20 M8).

Às vezes juntar todo mundo, conversar com todo mundo junto, que eu sei que as vezes é difícil juntar todos os professores, passar informação para todos eles, para padronizar um pouco mais entre eles, porque cada coordenador do PIC tem uma visão diferente, poderia tornar o processo mais contínuo (E15 M8).

Já o grupo que estava cursando do nono ao $12^{\circ}$ módulo apontou as seguintes sugestões de melhorias: capacitação dos professores, engajamento deles no processo de ensino-aprendizagem, cobrança mais efetiva em relação às atividades realizadas pelos alunos, controle mais acentuado no que concerne à participação dos discentes e avaliações mais justas com um padrão a ser seguido.

Os discursos desse grupo corroboram as falas dos grupos anteriores quanto à quantidade de alunos em sala de aula: os casos selecionados para discussão devem ser mais interessantes, o PIC não precisa necessariamente fazer parte do curso todo - o ideal é que ele se encerre com o início do internato - e a questão do horário em que ocorre o PIC:

Eu acho que capacitar os professores para eles saberem cativar os alunos e trazerem eles junto, os professores ajudarem a gente a aprender (E28 M11)

$5 \mid$\begin{tabular}{l|l} 
REVISTA BRASILEIRA DE EDUCAÇÃO MÉDICA \\
44 (4) : e161; 2020
\end{tabular} 
Portanto, evidencia-se, nos discursos dos estudantes de Medicina pesquisados, que todos os grupos corroboram as mesmas opiniões de sugestões de melhorias. Demostra-se, dessa forma, a real necessidade de capacitação para todos os professores que forem atuar na unidade do PIC. Isso comprova que, com a efetivação dessa sugestão, haveria resolutividade da maioria das sugestões propostas pelos acadêmicos.

\section{Características do aluno e do professor no PIC}

Sobre as características que o aluno do PIC deve apresentar ou adquirir para ter um bom desempenho nas aulas do PIC, o grupo do primeiro ao quarto módulo citou proatividade, compromisso, respeito pelos colegas e saber ouvir.

Tem que ser bem interessado no assunto e tem que ser alguém que é proativo assim basicamente, que gosta de estudar, olha os artigos (E5 M3).

Eu acho que tem que ser proativo, ele tem que ser curioso, ele tem que ser engajado, ele tem que ter vontade de buscar (E3 M3).

O grupo mencionou ainda outras características importantes para que o aluno apresente um bom rendimento nas aulas do PIC: saber trabalhar em equipe, ter disciplina e ter força de vontade e empatia.

Eu acho que trabalho em equipe é o primeiro ponto, eu acho que respeito, a gente tem que saber respeitar a opinião da outra pessoa, dar importância para áreas que não são nossas, eu acho isso bem importante. Eu acho que como ser humano $e$ profissional médico isso é muito importante (E6 M4).

Eu acho que tem que ser uma pessoa dedicada, que procura saber, tem que saber falar, expor o que aprendeu com as leituras e uma pessoa que também sabe ouvir, porque lá você está lidando com todo tipo de pessoa, com diferentes opiniões (E1 M1).

No grupo que estava cursando do quinto ao oitavo módulo, as falas mais recorrentes sobre as características que os alunos devem apresentar para ter um bom desempenho no PIC foram: estar disposto a estudar, ter interesse, estar comprometido e dedicar-se às atividades estabelecidas.

Eu acho que compromisso em primeiro lugar, ter compromisso de participar, de fazer o que é pedido, de chegar no horário, de cumprir com as obrigações. Acho que compromisso e dedicação pra mim são fundamentais (E15 M8).

Interesse! Cem por cento interesse! Uma pessoa que esteja interessada, ouvindo, participando, eu acho que seria assim a característica fundamental para o aluno dar certo no PIC. Tem muitos alunos desse jeito (E18 M8).

O grupo elencou outras características: falar em público, ter entusiasmo, ser empático, saber ouvir, ser crítico para realizar uma boa dispersão, não aceitar tudo que é imposto, ser criativo para desenvolver uma boa dispersão e ser curioso.

Então, primeiramente ele tem que já vir aberto a essa novidade, ter entusiasmo, tem a questão da empatia. Também tem a questão da comunicação que você aprende, mas você também pode lapidar ela durante o PIC (E16 M8).

Eu acho que ele tem que ser curioso, ter vontade de aprender. Acho que curiosidade mesmo de aprender diversas coisas e não só aceitar as coisas (E11 M5).

Já no grupo de alunos do nono ao $12^{\circ}$ módulos, não ocorreram narrativas divergentes dos dois primeiros grupos em relação às principais características que o aluno deve apresentar. As mais citadas foram: interesse e capacidade de falar em público. Nesse grupo identificou-se uma característica diferenciada dos demais grupos: o aluno deve ser "mente aberta" para poder entender e aceitar a dinâmica da metodologia.

Primeiro interessado, realmente saber onde procurar as informações, buscar as informações mesmo. Mas acho que o principal mesmo é o interesse (E23 M10).

Alguém que tem visão do mundo, cabeça aberta mesmo, que entenda a importância de saber as perspectivas de outros profissionais e de alguém que entende a importância de desenvolver a habilidade de falar em público. Na minha opinião alguém que tenha personalidade forte (E27 M11).

De modo geral, no que se refere às características necessárias para o aluno ter um bom desempenho nas aulas do PIC, constatou-se que ele deve ser proativo, demonstrar interesse, saber falar em público ou desenvolver essa habilidade, ser crítico, saber ouvir os colegas, ser comprometido e respeitar a opinião dos outros.

Quando se analisaram os relatos dos acadêmicos do primeiro ao quarto módulo a respeito da caraterísticas que o professor deve apresentar para que as aulas do PIC sejam eficazes e atrativas, elencou uma série de atributos, como: o docente deve fazer leituras prévias de artigos científicos para que todo o processe não seja baseado somente em vivências do dia a dia, respeitar as falas dos alunos e dos colegas e saber ouvir.

Eu acho assim, tem professor que, da mesma forma que a gente tem que pesquisar, ele também tem que pesquisar, se atualizar, porque se ele atualiza naquele tema, ele vai corrigir, ele vai acrescentar, ele vai falar o que falta. Por exemplo, a minha professora desse PIC agora, ela sempre lê, ela sempre atualiza, então é muito interessante (E6 M4).

Eu acho que tem que ser alguém que também vai pesquisar sobre $o$ assunto e que vai trazer algo para acrescentar. Algo diferente que a gente não tenha falado (E5 M3).

O grupo do quinto ao oitavo módulo demonstrou em suas falas os mesmos sentimentos do grupo anterior no que diz respeito à leitura prévia de artigos. Outras características elencadas por esse grupo foram: ter compromisso, ser assíduo nas aulas, ter interesse, ser justo e compreensivo com os alunos, saber conduzir os alunos, ser mais empenhados e criativo e não ser tímido.

Para mim, compromisso, porque esse negócio de faltar aos encontros sem avisar, eu não acho muito legal. Ter um pouco de compreensão com os alunos, porque tem professor que às vezes 
fica muito bravo se a gente chega com informação errada, mas a gente está aprendendo a pesquisar. Eu acho que um pouco de compreensão, de disponibilidade para ajudar na hora de fazer a dispersão, na hora de escolher um sub eixo (E15 M8).

Os estudantes que estavam cursando do nono ao $12^{\circ}$ módulo compartilharam da mesma perspectiva dos demais grupos no que se refere à leitura prévia dos artigos por parte dos professores. Além disso, mencionaram a importância de os professores se atualizarem, intervirem nas discussões e, consequentemente, estimularem os alunos a participar. Elencaram ainda várias outras características necessárias aos professores: problematizar, questionar, aceitar críticas, respeitar, ser interessado, dedicar-se e avaliar de forma justa.

Um pouco de interesse, fazer leitura, saber do que ele está falando. Porque já chegou professor lá na sala e falou: "Qual é o assunto de hoje?". Às vezes chegam sem saber nem o assunto (E23 M10).

Eu acho que eles deveriam fazer pesquisa igual a gente, acho que eles deveriam pesquisar e estimular mais os alunos a participarem, principalmente no grande grupo, porque no pequeno grupo você vai participar de um jeito ou de outro, saber fazer uma avaliação justa interpretando a situação (E22 M10).

As análises dos discursos evidenciaram características que, na percepção dos estudantes, são necessárias para ser um professor da unidade PIC que se utiliza da metodologia da problematização, são elas: leitura prévia de artigos científicos dos temas a serem discutidos, direcionamento nas discussões dos temas, ser proativo, interessado, questionador, problematizador e saber avaliar o aluno de forma justa.

\section{Contribuições do PIC para a formação médica}

Quanto à contribuição do PIC para a formação médica, todos os alunos do primeiro ao quarto módulo concordaram que o PIC, de alguma forma, será muito útil para eles. Os alunos referiram principalmente a questão da aquisição da habilidade de se comunicar. Ficou claro nas narrativas o quanto as aulas do PIC contribuíram e estão contribuindo para o desenvolvimento dessa habilidade.

O ponto de falar em público pra mim é o mais importante, porque, quando eu cheguei na faculdade, só com a possibilidade de falar em público eu já tremia, eu era muito introvertida e aí o PIC foi uma das primeiras coisas que me forçou a falar, porque eu queria tirar 10,0, então eu tinha que falar no grande grupo, e aí nossa, subia aquele calorão, eu gaguejava e melhorou bastante (E8 M4).

Esse grupo relatou ainda a importância das aulas do PIC no que se refere a aprender a pesquisar artigos. Os alunos descreveram que, por meio das aulas, aprenderam a trabalhar em equipe, a saber ouvir e a respeitar a opinião dos colegas, tornaram-se pessoas mais críticas e com pensamento de buscar resolver os problemas encontrados na sociedade, aprenderam a enxergar o paciente de forma holística, humana, e por fim relataram estar mais proativos. De acordo com as falas, fica claro que o PIC contribui de fato não só para a formação profissional, mas também para a formação humana dos acadêmicos.

Eu considero que é algo que pode acrescentar muito na nossa formação enquanto profissional e enquanto pessoa mesmo. Eu considero que ajuda a gente no nosso estudo, a gente aprende a estudar, a gente aprende a lidar com opiniões diferentes, a gente aprende a lidar com pessoas de áreas diferentes, eu acho que é como eu vejo o PIC (E6 M4).

Entre os alunos do meio do curso, do quinto ao oitavo módulo, houve uma convergência de narrativas que evidencia as contribuições do PIC para a formação médica. Descreveram também como predominante a importância do PIC para o desenvolvimento da habilidade de comunicação. Outro ponto muito citado nas falas foi a valorização de ser autodidata na busca de artigos científicos nas bases de dados. Referiram que, ao aprenderem a estudar e entender os artigos, conseguiram ter um melhor raciocínio crítico sobre o assunto para uma possível discussão fundamentada.

Ajudou muito a falar em público, na busca de conhecimento, pensar criticamente. Falar no grande grupo, de você ouvir, refletir e poder falar, discutir com aquela pessoa e ter síntese de fala (E20 M8).

Eu acho que melhora a parte de falar em público. Acho que melhora o meu raciocínio porque você discute, você escuta a palavra de muitas pessoas (E12 M5).

No que se refere à perspectiva dos acadêmicos do final curso, já no período do internato que vai do nono ao $12^{\circ}$ módulo, evidenciou-se uma forte contribuição do PIC para a formação do profissional médico. A contribuição mais citada também foi a habilidade de comunicação. Relataram que, no início do curso, tinham dificuldade de falar em público e que no momento já não conseguem mais enxergar essa dificuldade. Outras contribuições foram o desenvolvimento da habilidade de pesquisar e a busca pelo conhecimento, o que os tornou mais ativos, mais críticos nas discussões e mais resolutivos.

A primeira coisa foi de falar em público, eu realmente odiava falar com muita gente, mas com o tanto de apresentação de trabalho. O PIC também ajuda nesse sentido, a perder a inibição, realmente discutir assuntos práticos, um pouco nesse sentido, realmente é bom (E23 M10).

Como eu disse, na valorização de referência, aprender a pesquisar, aprender a falar em público é uma coisa boa. Mas, a principal questão de falar em grupo, pesquisar. E uma outra coisa é a presença da equipe multiprofissional que a gente aprende vários conhecimentos pontuais (E22 M10).

A análise dos discursos dos estudantes de Medicina acerca das contribuições do PIC para a formação médica evidenciou a contribuição de forma significativa para a formação profissional e humana dos alunos. Essa formação se inicia no primeiro módulo quando entram em contato com a disciplina do PIC, ficando mais evidente a percepção do desenvolvimento de habilidade importantes para um médico nos módulos finais.

$7 \mid$\begin{tabular}{l|l} 
REVISTA BRASILEIRA DE EDUCAÇÃO MÉDICA \\
\hline 44 (4) : e161; 2020
\end{tabular} 


\section{DISCUSSÃO}

O presente estudo identificou que o uso das metodologias ativas na unidade do PIC faz com que os alunos adquiram uma série de competências e habilidades no decorrer do curso. Entre elas, destacou-se a comunicação, principalmente no que diz respeito a falar em público.

A metodologia da problematização exige que os discentes façam atividades como expor seu ponto de vista em relação aos artigos pesquisados para o pequeno e grande grupos. Nessa exposição, devem apresentar hipóteses de soluções para os problemas elencados. Assim, treinam a comunicação e, com o passar dos anos, adquirem essa habilidade que antes era considerada uma dificuldade $\mathrm{e}^{17,18}$.

Em um estudo, cujo objetivo foi verificar o impacto da mudança do processo ensino-aprendizagem tradicional para as metodologias ativas, em que se elencaram as alterações do método tradicional para o ativo, constatou-se que a metodologia ativa exige o conhecimento de novos saberes do aluno, estimula o senso crítico e a responsabilidade e auxilia na aquisição de confiança ao longo do curso. Além disso, identificou-se que os estudantes tendem a adquirir habilidades de comunicação e liderança, tão necessárias ao profissional médico na tomada de decisões ${ }^{19}$.

O desempenho de determinadas habilidades e atitudes médicas se tornam mais presentes em alunos inseridos em um currículo orientado pelas metodologias ativas. Nesse contexto, os estudantes aprendem a ser resolutivos e críticos e a vivenciar situações problemas no dia a dia da comunidade ${ }^{20}$.

Com o uso das metodologias ativas, o aluno passa a ter mais autonomia sobre a própria aprendizagem e uma participação efetiva na sala de aula, já que as atividades dependerão de ações realizadas por ele. $\mathrm{O}$ aluno desenvolve maior confiança e autonomia, tornando-se protagonista do próprio aprendizado. $\mathrm{O}$ estudante deve ser incitado a participar de debates, expor sua opinião e resolver problemas reais. Trata-se de uma construção de conhecimento e não de uma reprodução do que já está pronto ${ }^{21}$.

Outro ponto forte foi a proximidade entre o aluno e o professor proporcionada pela metodologia da problematização. Essa proximidade nos pequenos grupos faz com que aluno e professor tenham maior afinidade, quebrando uma série de barreiras antes existentes entre eles.

O professor, em seu grupo, pode observar de perto cada aluno e enxergar as dificuldades e as facilidades apresentadas. Dessa forma, o docente pode ajudar o aluno de forma mais personalizada, haja vista que cada discente é único. Quando o professor vivencia as dificuldades e as facilidades do aluno, torna-se mais favorável traçar qual a melhor forma de ensinar ${ }^{18}$.

$O$ professor deve seguir a perspectiva do aluno e acolher seus pensamentos, sentimentos e atuações, sempre que manifestados. Deve ainda ajudá-lo em seu desenvolvimento motivacional e na capacidade para autorregular-se no âmbito da sala de aula. Desse modo, a criatividade e a responsabilidade são incitadas e apreciadas, o que pode resultar no desenvolvimento de graus de envolvimento, iniciativa, autoconfiança e autonomia. Essas ações são orientadas metodologicamente pelo professor, que admite a condução e articulação cuidadosa do processo. Isso significa que o professor deve agir como mediador e não como fornecedor de todas as informações ou autor de todas as decisões ${ }^{17}$.

Assim como os estudantes pesquisados elencaram pontos fortes, também mencionaram pontos frágeis, e o mais citado foi a não execução das ações de dispersão ou também chamada de devolutiva à comunidade. Para os acadêmicos, quando não se realiza a dispersão direcionada ao cenário de prática, não se completa o ciclo pedagógico inserido na metodologia da problematização. Essa não realização da devolutiva leva os alunos a perder o entusiasmo pelas aulas do PIC. Sem a devolutiva, perde-se o sentido pedagógico da metodologia da problematização.

O que parece mais característico da metodologia da problematização é o fato de o esquema do arco, apresentado por Charles Maguerez, dispor de uma etapa de retorno ao problema inicial, no intuito de modificar a realidade por meio da aplicação do conhecimento construído durante o processo ${ }^{22}$.

A relação teoria-prática é constante. O processo deve se completar por meio da realização de alguma intervenção que tenha como objetivo a resolução do problema inicial. Desse modo, todo o estudo ganha sentido, já que servirá de fundamentação e sustentação para uma ação prática concreta na realidade em que o estudante está inserido e de onde foi retirado o problema estudado nas aulas do $\mathrm{PIC}^{17}$.

Para que todas as etapas da construção do conhecimento preconizadas pela metodologia da problematização sejam cumpridas, cabe ao professor ser o mediador de todo o processo. Se os professores não entenderem a metodologia e a aplicabilidade do arco, ficarão lacunas que acarretarão prejuízo no processo de intervenção/construção de habilidades e atitudes e na aquisição de conhecimentos por parte dos alunos.

Em geral, os professores de Medicina foram formados pelo método tradicional e apresentam grande dificuldade para aprender a nova metodologia de ensino. Às vezes não acreditam na metodologia por não terem conhecimento suficiente ${ }^{23}$. As universidades devem investir mais em capacitações e educação continuada e cobrar de fato a presença de todos os professores para que participem e passem a entender a nova forma de ensino preconizada nas $\mathrm{DCN}^{23}$.

Em uma pesquisa, foi analisado o emprego das metodologias ativas de ensino, tendo como objetivo relatar as impressões e os resultados observados pelos docentes e a percepção da necessidade de integração das metodologias de ensino com as novas tecnologias de comunicação. Identificou-se que a utilização de plataformas online, casos reais ou qualquer outra estratégia que pressuponha estudantes ativos de sua aprendizagem só terá sentido se houver docentes comprometidos e coadunados com as expectativas de seus estudantes. Assim, vive-se um momento de transição que exige do docente uma profunda reflexão sobre a sua prática profissional, bem como espera-se que haja uma rápida adaptação deste à esta nova realidade de ensino e aprendizagem que se torna realidade no ensino superior brasileiro ${ }^{18}$.

Na perspectiva dos estudantes entrevistados, houve unanimidade nas propostas de melhorias sobre mais capacitação, treinamento e educação continuada dos professores que atuam no PIC. Essas sugestões apontadas pelos acadêmicos demonstram o quanto os alunos se interessam pelo processo de melhoria para as aulas do PIC.

Há a necessidade de implementação de novas estratégias que visem à capacitação e à educação continuada de todos os envolvidos no processo educativo, com vistas à integralidade teórico-prática na execução da metodologia da problematização. Sendo assim, é necessário que as instituições de ensino oportunizem cada vez mais aos docentes ferramentas didático-pedagógicas que visem à formação de profissionais críticos, reflexivos, questionadores e coadunados com a realidade social em que estão inseridos ${ }^{24}$.

A profissão docente, assim como as demais profissões, determina capacitação própria e específica. É fato que a atividade de educador vai muito além das funções de produzir e socializar o conhecimento. Para o 
cumprimento adequado da função de professor do ensino universitário, espera-se muito mais do que um diploma ou mesmo titulações, principalmente quando se refere às metodologias ativas ${ }^{23}$.

A preparação do corpo docente para a mudança deve ser construída de forma paulatina, pelos ciclos anuais de capacitação docente; é trabalhar as diversas metodologias ativas de ensino e, por fim, executar o projeto de mudança. Essa é a forma correta de implantar o projeto e capacitar os professores para a utilização das metodologias ativas ${ }^{18}$.

As dificuldades e os limites apontam para a necessidade de investimento constante no desenvolvimento profissional do professor universitário, uma vez que deixar a perspectiva das tradicionais aulas expositivas exige formação e capacitação docente. Como toda a metodologia ativa, a metodologia da problematização provoca o professor a sair de sua zona de conforto, preparar-se didática e pedagogicamente para o exercício da docência, em uma perspectiva investigativa e dinâmica ${ }^{25}$.

Foi possível evidenciar, na fala dos acadêmicos pesquisados, que as principais características que os professores devem apresentar para terem um bom desempenho nas aulas do PIC são: ser proativo, problematizador e questionador, gostar de metodologia ativa e ter preparo prévio. $\mathrm{O}$ exercício apropriado da atividade de professor de metodologias ativas exige muito mais do que um diploma ou mesmo as titulações de mestrado ou doutorado. $\mathrm{O}$ uso das metodologias ativas tem a vantagem de favorecer o aprendizado por meio das relações interpessoais e colaborativas e requer que o professor se prepare didaticamente ${ }^{26}$.

Cabe ao professor instigar, despertar, vincular e sensibilizar o aluno em relação ao elemento do conhecimento, partindo da sua percepção do objeto do estudo que leva para a aula. Essa prática problematizadora deve estar ligada a um processo crítico de questionamento, em que os professores questionam e estimulam os alunos a atentar à observação da realidade. $\mathrm{O}$ professor deve estar sempre estimulando o aluno para que sempre busque o conhecimento ${ }^{6}$.

É na ação que o professor demonstra suas capacidades, exercita suas possibilidades e atualiza suas potencialidades. As metodologias ativas são mais complexas na elaboração de seus objetivos e na aplicação de conteúdo. Elas demandam mais tempo de preparação, aplicação e avaliação de conteúdo ${ }^{8}$.

No que se refere à escola médica, é necessário que o professor pense na utilização de recursos didáticos que redirecionem o ensino para uma educação voltada à formação de um médico generalista, com qualificação para compreender o processo saúde-doença, pautando-se em uma postura humana, crítica, reflexiva e ética, que possa desenvolver ações nos diferentes níveis de atenção que possibilitem promover a prevenção, recuperação e reabilitação da saúde do ser humano, visando à integralidade da assistência, à responsabilidade social e ao compromisso com a cidadania8.

Conforme as DCN de 2014, o acadêmico de Medicina, ao final do curso, deve ser um profissional completo que apresente proatividade e seja crítico, reflexivo e resolutivo. Para que isso ocorra, é necessário que se utilize de metodologias que privilegiam a participação ativa do aluno na construção do conhecimento, a fim de promover a integração e interdisciplinaridade em coerência com uma proposta radical de formação médica voltada para a humanização e integralidade ${ }^{4}$.

A partir deste estudo, foi possível evidenciar, na percepção dos estudantes entrevistados, o quanto as aulas do PIC contribuem para a formação médica. As contribuições mais citadas no decorrer das falas dos acadêmicos foram: saber falar em público, tornar-se autodidata na busca de conhecimento, saber ouvir os colegas, trabalhar em equipe multidisciplinar e ser resolutivo.

Em um estudo sobre a metodologia da problematização nos cursos de Medicina, foi constatado que, por meio dessa metodologia de ensino, os alunos demonstraram um maior interesse e tiveram uma maior participação nas aulas e que a aproximação da teoria à prática fortaleceu a consolidação do conhecimento ${ }^{19}$.

No âmbito dessa metodologia, estudar uma situação-problema leva ao surgimento de novos desdobramentos, exigindo o conhecimento de outros saberes e a interdisciplinaridade para a solução. Tal fato tende a estimular o desenvolvimento do pensamento crítico e a responsabilidade do estudante pela própria aprendizagem. Sendo assim, essa metodologia auxilia na aquisição de confiança ao longo do curso e produz uma postura de liderança, necessária ao profissional que conduz a terapêutica mediante a tomada de decisões ${ }^{19}$.

A metodologia da problematização se baseia em um processo que visa aprender a aprender, que abre a possibilidade do diálogo, valoriza os conhecimentos prévios dos discentes e estimula-os a buscar, com autonomia, novas aprendizagens, de modo a torná-los profissionais mais críticos, reflexivos, resolutivos e humanos ${ }^{27}$.

A proposta da metodologia da problematização surge como forma de produzir experiências inovadoras, formando profissionais críticos que possam contribuir para o bem-estar da sociedade. A problematização possibilita a busca individual do conhecimento e a estruturação deste em equipe, por meio do levantamento de soluções. $\mathrm{O}$ acadêmico familiarizado com esse ambiente poderá empregar esse conhecimento em sua conduta de trabalho ${ }^{28}$.

Portanto, na metodologia da problematização, o professor deve suscitar nos estudantes o espírito crítico, a curiosidade, a não aceitação do conhecimento simplesmente transferido, tendo como pressuposto de que a aprendizagem acontece com a formulação e a reformulação dos saberes pelos estudantes ao lado dos professores. Fornece aos alunos condições para o desenvolvimento de habilidades técnicas, cognitivas e atitudinais que estimulam a autoformação, tão necessárias para a formação médica ${ }^{8}$.

\section{CONCLUSÃO}

A partir da percepção dos acadêmicos de Medicina entrevistados, foi possível evidenciar a eficiência no uso da metodologia da problematização na unidade do PIC, mesmo apresentando algumas dificuldades na execução da metodologia. Os estudantes descreveram a importância da utilização dessa metodologia de ensino para seu crescimento profissional e pessoal, embora ela apresente algumas lacunas que podem ser sanadas.

Constatou-se que a metodologia da problematização apresenta uma série de fatores fortes para a construção do conhecimento. Para os estudantes, há uma lacuna a ser reparada, que diz respeito à execução das ações de dispersão, que se constitui na última etapa do arco de Maguerez. Tal lacuna é atribuída à falta de mais capacitação de grande parte dos professores. Nesse contexto, foi sugerido que haja mais capacitação para todos os professores envolvidos no processo acadêmico e inseridos na unidade do PIC.

$\mathrm{Na}$ percepção dos acadêmicos, a metodologia da problematização na unidade do PIC apresenta mais pontos fortes que frágeis. Apesar do impacto inicial causado pelo desconhecimento da utilização da

REVISTA BRASILEIRA DE EDUCAÇÃO MÉDICA

9 44(4) : e161; 2020 
metodologia da problematização, com o passar dos períodos há uma adaptação. Esse entendimento leva os alunos a compreender que essa metodologia visa torná-los profissionais completos, que aprenderam a aprender, a buscar conhecimento, ser críticos, resolutivos e saber ouvir a opinião dos colegas de outras áreas.

A percepção dos estudantes é de grande importância, uma vez que são atitudes, habilidades e conhecimentos necessários ao egresso do curso de Medicina e que estão descritos nas DCN do curso. O presente estudo evidenciou sobremaneira as contribuições da funcionalidade e aplicabilidade da metodologia da problematização na unidade do PIC para a formação em medicina.

Como uma nova metodologia inserida no campo da formação médica, há fragilidades tanto na formação do aluno quanto na atuação do professor mediador. Os resultados aqui apresentados poderão servir para que os cursos de Medicina que se utilizam dessa metodologia possam fomentar estratégias que visem à sua integral aplicabilidade.

\section{REFERÊNCIAS}

1. Gomes MPC, Ribeiro VMB, Monteiro DM, Leher EMT, Louzada RCR. O uso de metodologias ativas no ensino de graduação nas ciências sociais e da saúde - avaliação dos estudantes. Ciênc Educ. (Bauru). 2010;16(1):181-98.

2. Costa JRB, Romano VF, Costa RR, Gomes AP, Alves LA, Batista RS. A transformação curricular e a escolha da especialidade médica. Rev Bras Educ Med. 2014;38(1):47-58.

3. Freitas CM, Freitas CASL, Parente JRF, Vasconcelos MIO, Loma GK, Mesquita KO, et al. Uso de metodologias ativas de aprendizagem para a educação na saúde: análise da produção científica. Trab Educ saúde. 2015;13(2):117-30.

4. Brasil. Resolução CNE/CES nº 3, de 20 de junho de 2014. Institui Diretrizes Curriculares Nacionais do Curso de Graduação em Medicina. Diário Oficial da União, Brasília; 23 jun. 2014; Seção 1, p. 8-11.

5. Marin MJS, Gomes R, Marvulo MML, Primo EM, Barbosa PMK, Druzian S. Pós-graduação multiprofissional em saúde: resultados de experiências utilizando metodologias ativas. Interface (Botucatu). 2010;14(33):331-44.

6. Villardi ML, Cyrino EG, Berbel NAN. A problematização em educação em saúde: percepções dos professores tutores e alunos. São Paulo: Cultura Acadêmica; 2015.

7. Berbel NAN. Metodologia da problematização: experiências com questões de ensino superior. Londrina: Eduel; 1998.

8. Carabetta Júnior V. Metodologia ativa na educação médica. Rev Med. (São Paulo). 2016;95(3):113-21.

9. Berbel NAN. Metodologia da problematização: uma alternativa metodológica apropriada para o ensino superior. Semina: Ciências Sociais e Humanas. 1995;16(2):9-19.

10. Abreu JRP. Contexto atual do ensino médico: metodologias tradicionais e ativas - necessidades pedagógicas dos professores e da estrutura das escolas [dissertação]. Porto Alegre: Universidade Federal do Rio Grande do Sul; 2009.

11. Sacchetim SC, Major CR, Mendanha DBA, Teles AA, Souza FHC, Sandes MTS. Percepção docente da aprendizagem baseada em problemas - Medicina UniEVANGÉLICA. Rev Educ saúde. 2012;1(1):10-7.
12. Aragão J. Introdução aos estudos quantitativos utilizados em pesquisas científicas. Rev. Práxis. 2011;3(6):59-62.

13. Canzoniere AM. Metodologia da pesquisa qualitativa na saúde. Petrópolis: Vozes; 2010.

14. Triviños ANS. Introdução à pesquisa em ciências sociais: a pesquisa qualitativa em educação. São Paulo: Atlas; 1987.

15. Dantas CC, Leite JL, Lima SBS, Stipp MAC. Teoria fundamentada nos dados - aspectos conceituais e operacionais: metodologia possível de ser aplicada na pesquisa em enfermagem. Rev. Latino-Am. Enfermagem. 2009;17(4):573-9.

16. Tjitra H. Grounded Theory. Hangzhou: Zhejiang University; 2012.

17. Berbel NAN. As metodologias ativas e a promoção da autonomia de estudantes. Semina: Ciências Sociais e Humanas. 2011;32(1):25-40.

18. Rocha INV, Amaral EA. Metodologias ativas de ensino: percepções da aplicação no curso de direito. In: Andrade Júnior JM, Souza LP, Silva NLC, organizadores. Metodologias ativas: práticas pedagógicas na contemporaneidade. Campo Grande: Inovar; 2019. p. 96-113.

19. Souza CFD, Roziska IM, Albuquerque, T, Freitas CF, Luzardo R. O impacto da mudança do processo de ensino-aprendizagem tradicional para a metodologia ativa: um relato de experiência. Rev Uniabeu. 2016;9(23):162-77.

20. França Júnior RR, Maknamara M. A literatura sobre metodologias ativas em educação médica no Brasil: notas para uma reflexão crítica. Trab Educ Saúde. 2019;17(1):e1801214.

21. Sahagoff APC. Um estudo sobre práticas pedagógicas. In: Andrade Júnior JM, Souza LP, Silva NLC, organizadores. Metodologias ativas: práticas pedagógicas na contemporaneidade. Campo Grande: Inovar; 2019. p. $140-152$.

22. Santana E B, Valente JAS, Freitas NMS. Metodologia da problematização: o uso de situações problema no ensino de anatomia. Exitus. 2019;9(1):175-201.

23. Silva CP, Lima TG. Metodologia ativa no ensino técnico profissionalizante e ensino superior: uma análise das vantagens e contribuições na formação dos educandos. In: Andrade Júnior JM, Souza LP, Silva NLC, organizadores. Metodologias ativas: práticas pedagógicas na contemporaneidade. Campo Grande: Inovar; 2019, p. 96-113.

24. Ramos KR, Menezes RMV, Mesquita SKC. Metodologias ativas de ensino/aprendizagem: dificuldades de docentes de um curso de enfermagem. Trab Educ Saúde. 2016;14(2):473-86.

25. Vieira MNCM, Panúcio-Pinto MP. A metodologia da problematização (MP) como estratégia de integração ensino-serviço em cursos de graduação na área da saúde. Rev Medicina. 2015;48(3):241-8.

26. Melo RA. A educação superior e as metodologias ativas de ensinoaprendizagem: uma análise a partir da educação sociocomunitária [dissertação]. Americana: Centro Universitário Salesiano de São Paulo; 2017.

27. Vilas Bôas LM, Daltro MR, Garcia CP, Menezes MS. Educação médica: desafio da humanização na formação. Saúde Redes. 2017;3(2):172-82.

28. Pereira TO, Lescano FA, Rocha KF. A aplicação de metodologias ativas em um programa de residência multiprofissional. In: Andrade Júnior JM, Souza LP, Silva NLC, organizadores. Metodologias ativas: práticas pedagógicas na contemporaneidade. Campo Grande: Inovar; 2019. p. 9-16.

\footnotetext{
$10 \mid$\begin{tabular}{l|l} 
REVISTA BRASILEIRA DE EDUCAÇÃO MÉDICA \\
\hline $44(4)$ : e161; 2020
\end{tabular}
} 


\section{CONTRIBUIÇÃO DOS AUTORES}

Rejane de Carvalho Santiago, Vardeli Alves de Moraes e Rogério José de Almeida participaram da concepção e do planejamento do projeto de pesquisa, da coleta de dados, da análise e da interpretação dos dados, da redação e da revisão final.

\section{CONFLITO DE INTERESSES}

Os autores declaram não haver conflito de interesses neste estudo.

\section{ENDEREÇO PARA CORRESPONDÊNCIA}

Rejane de Carvalho Santiago. Avenida Universitária, 1440, área 4, bloco K, Setor Universitário, Goiânia, GO, Brasil. CEP: 74605-010.

E-mail: rejane988@gmail.com 